\title{
The Iconic Order of the Autistic Communication-Speech Disorders
}

\author{
Michal Ephratt ${ }^{1}$ \\ University of Haifa
}

\begin{abstract}
This paper is devoted to the study of autistic speech from the perspective of iconicity. Language is a major means of human I-not-I interaction and communication. When there is affinity between content and the form designating it, this form (linguistic units and their organization) is said to be iconic to that content. Looking at the various modes of linguistic iconicity (from the phonetic level to the entire discourse, and from identity and continuity to modes of resemblance and analogy), milestone autistic denominators are detailed and analyzed as they occur in an authentic diary written over three years by a woman with autism. This article offers a look at echolalia; pronoun management; perception of affinity as exemplified in the use of kinship terms; content words vs. grammar markers, neologisms and other phenomena. These findings are then integrated to show that mutism is the most authentic - and iconic - mode enacting the traumatic autistic rupture of the delusory symbiotic state. In this premature frail encapsulation the counter-iconic use of language is in itself a pseudo use. By treating both language (phones, words, idioms, discourse, etc.) and people as things, the verbal oddities of autistic speakers authentically iconize the inauthentic inanimate stance.
\end{abstract}

In memory of Hadar, my autistic triplet twin - with love.

\section{Introduction}

Iconicity is a quality of affinity between content and the form designating it. Semiotics, following Charles Peirce (1965) classifies signs into three cardinal categories: firstness: identity (pure icon); secondness: resemblance (index) and thirdness: analogy mediated by convention (symbol). Linguistic iconicity may manifest itself along the different linguistic levels: from the single phone to the entire discursive interaction.

Mankind has long used signs to communicate. Visual signs have existed from prehistoric periods of human development. The color red depicting the very content of danger: blood and fire, is a visual sign currently used all over the world to warn or prohibit. Philosophers and linguists disagree about the iconic quality of words. In his dialogue

${ }^{1}$ Correspondence concerning this article should be addressed to Prof. Michal Ephratt, Department of Hebrew Linguistics, University of Haifa, Haifa 3498838, Israel. E-mail: mephrett@research.haifa.ac.il 
"Cratylus" Plato presented two opposing approaches: one claiming that the relations between the signifiers (phonetic strings) and the content they denote are arbitrary and conventionally determined (in every language and in each era); the other arguing for a necessary, and hence natural, intrinsic affinity between the content and the particular signifier denoting it. Onomatopoeia - mimicking the sound produced by an object in the real world by using the sound system (phonemes) of a language (signifiers) to denote that referent (such as "cock" or "bottle") - employs phonetic acoustic iconicity (image). A different kind of iconicity (diagram) operates with resemblance of characteristic features or qualities, such as the parallel between the syntactic ordering of words and of constituents in a sentence and the temporal or thematic sequence of the events in reality described by those words or sentences.

Following Frances Tustin (1992, p. 9), the term 'autism' covers "a specific spectrum of disorders in which there is an absence of human relationships and gross impoverishment of mental and emotional life". These impairments, she argues, result from "the blocking of awareness by an early aberrant development of autistic procedures". Lacking clear neurobiological markers autistic spectrum disorder (ASD) are necessarily described in behavioral terms (Lord \& Spence, 2006, p. 2; DSM-V, 2013, pp. 50-59). Language present or absent - plays a central role in the behavior, diagnosis and assessment, as well as in the treatment of individuals with ASD. ${ }^{2}$

Considering the various modes of linguistic iconicity (from the phonetic level to the entire discourse, and from identity to different modes of resemblance and analogy: secondness and thirdness) the emergence of autistic etiology in autistic speech is outlined. This article offers a detailed look at different types of echolalia; pronoun management (especially regarding I-not-I); perception of affinity as exemplified in the use of kinship terms, and content words vs. grammar markers reflecting soft vs. hard.

2 Kasher and Meilijson's deliberate decision to restrict their paper "Autism and Pragmatics of Language" (1996) to the reduction of the autistic core impairments to terms of the knowledge required for the various pragmatic categories as they surface in the utterances produced by autistic speakers, irrespective of the autistic etiology, results in a seemingly correspondence between their description and the autistic denominators listed in the DSM-V. Nevertheless, the objective of the DSM being a diagnostic tool is to establish the set of externally perceived symptoms, and so it is not expected to engage in issues such as etiology and causes; Kasher and Meilijson's decision seems unjust. Due to space limit, we are unable to refer to their specific arguments. We suffice here expressing our hope that the current discussion, integrating psychoanalytic conceptualization with linguistic tools will make apparent the necessity to tie linguistic observations concerning autistic linguistic behaviour with clinical conceptualization. Doing so shows that what surfaces as pragmatic oddities, are not, as Kasher and Meilijson argue mental representations shortcomings and matters to do with knowledge and skills, but the iconic manifestations of the autistic separation-individuation state and trauma. Pragmatics viewed, following Kasher and Meilijson, "as the linguistic conditions of appropriate use of sentences in context", these oddities seen from the autistic ruptured context turn out to be not only the most appropriate but iconically imaging that state.

Language and Psychoanalysis, 2015, 4 (1), 4-30

http://dx.doi.org/10.7565/landp.2015.001 


\section{Methodology}

\section{Data}

The empirical data for the study comes from an authentic handwritten diary and a few letters written between 1991 and 1998 by Hadar Ephratt, supported by my intimate and firm familiarity with her oral style. Hadar (1956-1998), after on- going withdrawal since the age of two, was finally diagnosed with autism at the age of six. ${ }^{3}$ She lived her entire adult life in a hostel (Beit-Ganim residence for independent adults with autism in Jerusalem) and worked at Meital (sheltered occupational center for persons with autism). Hadar turned to the diary - notebooks as well as occasional loose sheets of paper - at work and at home, particularly in the last three years of her life when she was coping with breast cancer. The diary consists of hundreds of pages covered in a childishly large handwriting (see below Illustration 1), the graphemes do not accord with the conventional spelling of the words: rather both spelling and spacing follow the sound of speech. The material is authentic: not only isn't it edited (by Hadar or others) ${ }^{4}$ but also, her diary style, lacking register competence ${ }^{5}$ - in flow, grammar and wording - is identical to her oral (spoken) style (see note 16 below concerning the letters). There are no punctuation marks throughout, except for a full stop at the conclusion of each entry - narrative chunk - stating "zehu". (that's it.).

\section{Qualitative Analysis}

Mapping excerpts of autistic speech onto iconic qualities of the autistic etiology, involves three facets: language, iconicity and autism. The next section (pp. 7-24) presents and locally analyses the findings from the data, classified according to the degree of iconicity between the specific documented autistic speech (text) and the micro autistic signifiers and states (outlined, e.g., in DSM-V, 2013, pp. 50-59). After that (see pp. 24-27) we synthesize the above groupings and analysis into an integrated picture of the autistic etiology as studied and described in the literature.

3 Hadassa Lascar Institute in Jerusalem. Though autism was described (by Kanner back in 1943 and by Asperger in 1944, it entered the DSM only in 1980 (DSM-III). In 1962 the assessment of autism was quite new among Israeli professionals (see e.g., Davidovitch et al., 2013), hindering diagnosis especially in cases such as Hadar's, whose autism was veiled by substantial vocabulary and high cognitive capabilities (see Kanner, 1943 and Asperger, 1944).

${ }^{4}$ Editing is a serious obstacle when attempting to utilize published diaries for the study of the language of autistic persons (see e.g., Sellin Birger, 1993 [1994]).

${ }^{5}$ Register competence is the ability to select between various styles (lexicon and grammar) according to the purpose of communication (diary, letter, the intimacy between the interlocutors (formal, informal) and the medium (such as written, oral, face-to-face or mediated). This lack of register competence might be a case secondary to the autistic state, e.g., resulting from matters to do with tuition, knowledge and learned skills. Not directly originating from the autistic state this too fails to count as support for Kasher and Meilijson's (1996) arguments - see note 2 above.

${ }^{6}$ For notation and translation, see note 9 below.

Language and Psychoanalysis, 2015, 4 (1), 4-30

http://dx.doi.org/10.7565/landp.2015.001 


\section{Analysis of the Linguistic Iconicity of Autistic Speech}

One of the milestone denominators of autistic objects is their odd use, a use unlike their common or original function (Kanner, 1973, p. 246; Asperger, 1944, p. 81; Tustin, 1992, p. 5; Amir, 2014, p. 70, see excerpt [14] below, and the quote from Bosch (1970, p. 93) following excerpt [21]). It is, then, not surprising that autistic speech too shows similar peculiarities. Language as a mode of interaction necessitates three elements: two interactants and a need. This is how Amir opens her book Cleft Tongue: The Language of Psychic Structures:

Language is first and foremost a depressive achievement involving both the concession of what cannot be articulated - and the giving up of the symbiosis with the other by acknowledging him or her as a distinct subject. Indeed, acknowledging separation is simultaneously the driving motivation to speak as well as an essential condition for establishing language (2014, p. 1, see also Tustin, 1992, pp. 78-80).

The infant, then acquires and integrates language while it becomes differentiated as a separate self. This separation, which takes place at the formative age between 2 and 3 (referred to as "the Oedipus complex" or by "the introduction to the parental order"), makes absences apparent, thus motivating the call to the other (see Amir, 2014, pp. 1-30; Bosch, 1970, pp. 85-87).

\section{Autistic Muteness as Pure Icon}

Autism - when the route of I-not-I differentiation is prematurely cut - surpluses language altogether. Individuals with autism, who do not speak, iconically, reflect as such the autistic state of being. This iconic mode of reflection lacks the necessary two-fold quality of a sign: separate and independent content (referent, the 'what') and form (signifier, 'how'). In the absence of separation between form (psychic mutism) ${ }^{7}$ and content (confused immature separation, and with no integrated self, which is thus cut-off from the experience of absence and needs) autistic mutism does not signify the autistic state but is the autistic state per se. Peirce's pure iconicity (firstness), being undifferentiated (such as the a feeling), does not constitute a sign $(1965,2.92 ; 2.276 ; 3.1)$. Autistic mutism is not a form the person with autism uses to communicate her state (by way of the content) - it is one and the same with that state.

\section{Autistic Speech as Iconic Imaging of the Autistic State}

Since it is a systematic convention of signification, language falls outside Peirce's pure icon (firstness). When iconic, language signs can only result in iconic signs of secondness

\footnotetext{
${ }^{7}$ As DSM-V (2013, p. 51 E) and scholars point out organic or cognitive impairments must first be ruled out. 
and thirdness. ${ }^{8}$ The muteness of the person with autism is not only a symptom, which belongs according to Peirce in the category of indices, i.e., "a sign which signifies its object solely by virtue of being really connected with it" (1965, Book 3, p. 211, Book 2, p. 179) but a pure icon of the autistic state of being, while autistic speech - the object of our investigation - is counter-iconic. Kanner (1943, p. 243) argues that as far as the communicative functions of speech are concerned, there is no fundamental difference between a speaking person with autism and a mute person. We now investigate the semiotic relations holding between the autistic states and the selected typical linguistic behaviors emerging in autistic speech: our first sub-section focuses on echolalia (pp. 810); we then focus on similarity (pp. 10-20) and conclude looking at analogy (pp. 20-24).

\section{The iconic qualities of echolalia}

Among "[r]estricted, repetitive patterns of behavior, interests, or activities" the DSM-V (2013, p. 50) specifies as DSM denominators "[s]tereotyped or repetitive [...] use of objects, or speech (e.g., simple motor stereotypies, lining up toys or flipping objects, echolalia, idiosyncratic phrases)" as well as "[i]nsistence on sameness, inflexible adherence to routines, or ritualized patterns of verbal or nonverbal behavior".

In essence, echolalia - immediate or delayed echoing of speech (others' or one's own words or phrases) - conceptually covers all the verbal behaviors outlined in the above quote from the DSM. The surface outcome is thus one and the same.

Manifest in speech (verbal-linguistic signs) echolalia does not seem to fit with Peirce's pure icon. Despite the speaking-autistic person's diffuse separateness and disintegrated self (depriving her of the two conditions motivating communication and speech) she does speak, mostly using conventional words and phrases. Further examination of the verbal phenomena listed in the DSM under echolalia, shows that it should be considered as being situated in between symptomatic - index, i.e., associated by contiguity, and -on the other hand - verbal sign which iconically images the autistic states (secondness) or is analogous to them (thirdness).

Reading through hundreds of pages of Hadar's diary, echolalia is prominent: it forms the macro raison d'être of writing the diary and from there on reaches down to the lexical micro level. As she disclosed in the diary it served as a medium for the reproduction of particular texts/narratives over and over again. These pages were not written with a reader (herself or others) in mind. Their writing served the same local and immediate function as any other repetition, such as rocking back and forth on the chair (see the DSM list cited above): soothing and reassuring through repetition. Clearly to this end the semiotic quality of language, namely the communicative use of the signs to convey (to the not-I) content via form is irrelevant.

8 Physiologically derived sounds, and thus not meant to communicate (they are not a cry for help), genuine exclamation words, are according to Peirce's categorization indexes integrated into the lexicon as linguistic elements. "Ouch", an authentic pain cry, is a canonical example: rather than a sign (onomatopoeic or otherwise) denoting trouble, it is distress as such. Being a sound produced by opening the mouth wide to instantly inhale oxygen for the distressed body, it is a symptom (associated by contiguity, and not by resemblance with its object).

Language and Psychoanalysis, 2015, 4 (1), 4-30

http://dx.doi.org/10.7565/landp.2015.001 
Excerpt [1] illuminates the characteristic echolalia:

[1] kaasher hayiti Gan Olami [...] asu li et ha-shkiat dam ha-dkira ba b-tor haftaa az oto zman Miryam ha-ozeret natna cvitat xiba b-taut baxiti shfoferet mayonez bayit im gag adom ${ }^{9}$

Gloss: ${ }^{10}$ When [I] was (ps. 1p sg.) \{in\} Olami Kindergarten [...] did (subjectless 3p pl. imprs., =gave me) the blood sedimentation test $\{$.$\} the puncture came as [a] surprise$ s.\} $_{\text {. }}$ then same time Miryam the cleaning lady gave (omission of syntactic object: herself as recipient) [an] affectionate pinch by mistake $\{\}.[\mathrm{I}]$ cried (ps. $1 \mathrm{p} \mathrm{sg.)}\{:\}{ }^{\left\{{ }^{\prime \prime}\right\}}$ mayonnaise tube $_{\{.\}}[\mathrm{a}]$ house/home with [a] red roof $\left\{.{ }^{11}{ }^{11}\right.$

As apparent, not only were the fixed, stuck-together, idiosyncratic compounds "mayonnaise tube" and "[a] house/home with a red roof" unrelated to each other, they were also unrelated to the specific context. In stressful situations or when Hadar deliberately tensed herself, she produced them for the sake of repetition. As a ritualized verbal pattern (detached of any lexical meaning) this example of echolalia constitutes not only a symptom (form connected with object by cause and effect relations) but also a pure icon (associated by identity - lack of separation) of the autistic state.

As indicated in DSM-V, echolalic ritualized verbal patterns are a subclass of other (nonverbal) ritualized patterns. As is the case here, such verbal patterns may initially have been created by the autistic speaker, but by ritualizing them the option of a new production is blocked (see also Amir, 2014, pp. 76-90). Moreover, the autistic state of detachment from the experience of self makes the issue of source - whether it is the speaker's own text; idiomatic literary language, or someone else's regular (nonpathological) speech - immaterial. Accordingly, the person with autism experiences the repetition of her own speech in the same way as she experiences observing her own photos (see [7] below). As it is an external retrieval of ready-made speech, echolalia contrasts with spontaneously generated speech. Such stereotyped speech is external to the unique situation and context.

This brings us to echolalia not as a pure icon but as a diagram (secondness) in which the repetitive quality of the linguistic signifiers iconically resembles their referents (contents).

${ }^{9}$ For each excerpt, a broad transliteration of the Hebrew text is followed by an English glossary equivalent of the idiosyncratic content and form. Inevitably, the gloss appears as ungrammatical, incomplete or otherwise deficient odd sentences (see note 4 above). For convenience, proper names are capitalized in the transliteration.

10 Gloss notations: round brackets are reserved for additional grammatical information; square brackets are used to list linguistic elements implicit in the Hebrew grammar but explicit in English. For clarity essential punctuation marks, prepositions and conjunctions were added in curled brackets.

Abbreviations of grammatical information (mainly regarding inflection): first person $=1 \mathrm{p}$; second person $=2 \mathrm{p}$; third person $=3 \mathrm{p}$; past $=$ ps.; participle $=$ prtc.; future $=\mathrm{ft}$; impersonal (neuter) = imprs.; singular - sg.; plural = pl.; masculine $=\mathrm{ms}$. and feminine $=\mathrm{fm}$.

11 On the significance of these events, see pp. 20-22 below.

Language and Psychoanalysis, 2015, 4 (1), 4-30

http://dx.doi.org/10.7565/landp.2015.001 
A phenomenon typically associated with autistic echolalia involves self designation. As detailed below (see pp. 10-16) not all forms and incidents of shifted pronominal deixis should be attributed to echolalia. Still, some incidents of the use of second person pronoun to designate oneself clearly originate in echolalia. Such is Hadar's invariable use of an enclitic second person suffix when she tells of harmful or negative incidents resulting from (deliberate or uncontrolled) deeds in which she has been the agent. She then uses formulaic Hebrew collocations such as "ole lak al ha-acabim" (E: gets on your nerves, see [9] below); "biglalek" (E: owing to you) and "lo letaamek" (E: not to your taste) - all in the second person, as if replicating the negative comments she received (in response to her reprehensible deeds) but without adjusting perspectives to herself as the thematic object, which would require grammatical first person.

\section{Secondness}

Peirce's secondness consists of signs in which form resembles content but is not identical with it. Such resemblance could be similarity between the signifier and the referent, or similarity between significant features of the form and qualities of the referent. Secondness is exemplified here by the autistic iconic use of person pronouns and markers (I not-I, pp. 10-16 below) and content words vs. procedural (structural) grammar markers (soft vs. hard relations, pp. 16-18 below).

\section{Modes of designating oneself which iconically image the autistic state}

As mentioned a key verbal behavior associated with autism is the "use of 'you' when referring to self"' (see DSM-V, 2013, p. 54).

Communication and the use of language in general, and the symbolic (non-echolalic, see above) use of the pronoun "I" - referring to self, the first person speaker in particular necessitates an internal notion of self, yielding differentiation between I and not-I. In view of the process of intrapsychic development, it is no coincidence that in normal language acquisition infants master this faculty around the formative age of 30 months (see e.g., Bosch, 1970, p. 109; Cruttenden, 1977; Clark, 1978; Berman, 1985, pp. 273, 303-308). First person pronoun markers are unique in that in any possible normal-natural context (excluding artificial situations such as an actor on stage, or when one quotes direct speech) it is only the individual speaker who can use first person pronouns and markers, and when doing so she necessarily refers to herself. In contrast with second, third and impersonal pronouns (such as "you" "she", "we" or zero [Ø]) no two speakers can use "I" (or "me", "mine") to designate one and the same person. This is why the appropriate use of "I" cannot be grasped and learned by rote mimic. The infant does not hear "I" referring to itself. Apart from integrated self, separation and grammatical competence, the successful acquisition of first person markers requires flexibility supported by play and inference.

Bosch (1970) points out that (what he terms) the confusion of personal pronouns in autistic language is consistent and regular (by no means random), springing, according to him, from the autistic etiology and state. Contrary to typically developing infants' initially mixed use of pronouns, autistic speakers do not only persist in this behavior but also, as Bosch pointed out, stick to a replacement of "you" for "I" but not the reverse (see e.g., Tustin, 1992, p. 54). 
The establishment of a mature notion of self - I not-I - becomes manifest in the distinctive choices a person makes between the possibilities offered by the grammatical and pragmatic system (see Kasher and Meilijson, 1996, but see note 2 above). Hebrew, being a synthetic (heavily morphologically marked) language, offers rich options. Grammatical markers indicating pronominal forms for deixis indicating the speaker's perspective emerge in the morpho-syntactic inflection of verbs (tenses); in an explicit pronominal form and in its subject syntactic agreement with the verb and in the object's (dative possession, patient) case roles (Berman, 1985). Moreover, verbs and adjectives are usually marked for gender. Usually, we say, because when we face or hear the subject speaking of herself (first person) this grammatical information is pragmatically redundant, and so no grammatical marker designating the first person is marked for gender.

This morpho-syntactic richness constantly compels the young Hebrew speaker to take a stand: to identify in each event and utterance the grammatical relations and qualities (including gender) which hold between her as a speaker and the participants and objects occupying the various syntactic roles. This entails intricate manifestations of self-imaging in the speech of Hebrew speaking persons with autism. The choice of signs - personal pronouns and markers - is iconic to the pragmatic locus (I-not-I) of the speaker. Being part of an acquired language signification system it is beyond the quality of pure icons.

First person markers when referring to others - be it the addressee or a third person were categorically non-existent in Hadar's oral speech and diaries (see note 16 below), and so this reversal was no option in her pragmatic-grammatical inventory. The fact that when referring to herself she used first person markers such as "ani" (E: I); "- $i$ " enclitic suffix for verb past tense inflection and object pronouns (E: "me"; 'mine') as one option, by no means reduced her use of second person, third person (including her own proper name, at times followed by her family name) forms, as well as the impersonal form and inanimate pronouns to refer to herself. In fact, in light of the standard obligatory use of first person markers in the appropriate pragmatic circumstances her use of first person as one option among a rich inventory is iconic, and so telling.

\section{[2] bikashti lhitkaleax levad b-kohot acmex}

Gloss: [I] asked ("-ti”: ps. 1p sg.) to shower alone on her own (“-ek": $2 \mathrm{p}$ fm. sg., literally: with her own power) $)_{\{.\}}$

Excerpt [2] exemplifies some of the options Hadar used to refer to herself. Even though an explicit realization of the subject role: "ani bikashti" (E: I asked) is quite common in Hebrew, the obligatory realization of first person singular verb inflection ("- $t i$ " "bikashti") unequivocally determines the subject (as the speaker) making the subject's explicit mention redundant, so that it is often left out. This phrasing coincides with standard conversational and written Hebrew. The grammatical and lexical choices made so far iconically match the message: an independent (separate) self wishing to shower an activity conducted in privacy - unaccompanied by others, relying on her own abilities. But the use of the second person "acmex" (in place of the expected first person "acmi") challenges the entire picture. This phenomenon attested throughout the corpus rules out parapraxes or a grammatical agreement error or a pragmatic shortcoming (see note 2 above). In the specific context of [2] it seems to result from the autistic state perpetuated by echolalic segments (see above). 
[3] b-ikar ein li al ma lihyot lehuta zehu ha-goral shel Hadar v-nosaf l-ze at isha mevugeret bat4l kimaat zkena [...] zehu ha-mazal ha-ra shel Hadar lo ba mi-ha-leida vgam regishut yeter $[\ldots]$

Gloss: Mainly there is nothing for me to be enthusiastic (prtc. fm. sg.) about ${ }_{\text {\{.\} }}$ that's Hadar's fate $\{;\}$ and in addition you [are a] grown[-up]/adult woman aged41 almost [an] old [woman] [...] that's Hadar's bad luck \{.\} \{it did\} not come (ps. 3p ms. sg.) from the birth and also hypersensitivity [...]

Excerpt [3] illustrates three modes standing here for self reference: the standard dative first person article " $l i$ " (E: me); her proper (given) name "Hadar" (twice) and the object second person feminine pronoun " $a t$ " (E: you, fem. sing.). Customarily, speakers would state their proper name (given name, possibly followed by their family name) only in the mode of introduction. The speaker may mention her addressee's name (but not her own) as the second person referent of the vocative case, i.e., for addressing that addressee or drawing her attention. A third person's name is commonly used by the speaker to refer to that person.

Unlike with the use of second person above (see pp. 8-10), the content and grammar of [3] clearly rule out echolalia as an explanation. This is a narrative Hadar kept telling herself. The use here of second person and given name (third person) iconically images the content of her utterance as well as her alienated state: lacking a sense of self, and thus feeling no control over her own fate. ${ }^{12}$

A moving expression of detachment and relatedness to self is articulated, iconically using "recited" first person, proper name ("our Hadar") in the following excerpt in which she relates to her coming death:

[4] ani roca lamut kaasher yihye b-mea v-esrim b-kever shaxor axarei ha-bdika b-yom rishon ha-rofim lexlitu ken ishpuz b-Shaare Zedek o Hadaasah Ein Karem od nituax lhoci et gush yesh li xaze nituax plasti mi-ze yakol lamet yekola lamut ze az nigmar Hadar shelanu [...] vilava shelax shaa 9 ba-boker bi-mkom ze tavo xanixa xavera xadasha shma gam Hadar b-gil yoter cair bat shmone esare [...]

Gloss: I want (prtc. sg. fm.) to die when be (ft. 3 p ms.) in hundred twenty in [a] black tomb $b_{\{.\}}$after the check up on Sunday the doctors decided ( $3 \mathrm{p}$ pl. typos.) yes to hospitalization in Shaare Zedek or Hadassah Ein Kerem (medical centers) another operation to remove the lump I've got chest plastic surgery from this (one) can die (ms.) (one / I ) can die (fm.) ${ }^{13}$ from this $\{$.$\} so finished (over) with our Hadar [...] your$

12 Hadar's statement in [3] that she was not, so to say, born into this state, is one of many texts in which Hadar grants us an innocent first-hand report of the autistic state, which matches - and so supports - academic studies and theses concerning autism and persons with autistic spectrum disorder (see e.g., Kanner, 1943, p. 250, see also note 23 below).

13 The psycholinguistic (as well as metalinguistic) notion of "repair" entails I not-I awareness, as if to say: I produced an erroneous utterance and in order to get my message successfully across to my addressee I must repair this shortcoming (see e.g., Keen, 2003). Throughout hundreds of pages of Hadar's writing, she never crossed out a single word. "Can die (fm.)" immediately following "(one) can die (ms.) Language and Psychoanalysis, 2015, 4 (1), 4-30 


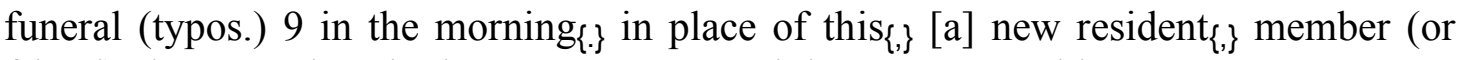
friend) also named Hadar in [a] younger age eighteen [years] old [...]

Hadar uses various modes to refer to her (dying) self: explicit first person subject position "I"; first person possession (I've got = my lump); subjectless: "Ø can die" (I can die); impersonal (neuter) and proper name "finished with our Hadar" (see [4a] below); second person (your funeral) as well as inanimate pronoun ("instead of this": me) referring to herself.

Excerpt [4a], drawn from a different notebook of the diary, presents the same narrative but offers other verbal means and context:

[4a] maxar horidu et tfarim tamuti lo yihye yoter Hadar nexapes Hadar xanixa axeret xadasha

Gloss: Tomorrow removed (subjectless ft. $3 \mathrm{p}$ pl. imprs.) stitches $\{$.$\} die (subjectless \mathrm{ft}$. $2 \mathrm{p} \mathrm{sg.})_{\{,\}}$not be (ft.) Hadar anymore ${ }_{\{,\}}$search (ft. 1p pl.) Hadar another new resident ${ }_{\{.\}}$

The self-reference in [4] and [4a] which is iconic to the autistic state, is immensely amplified in light of the content of these excerpts. Facing (early) death and lacking the sense of self and of holding, a form of continuance - such as in the memory of others - is not perceived as an option. Her use of "our" (our Hadar) in [4] and "another" ("another Hadar") in [4a] as if to narrow the semiotic/pragmatic extension of "Hadar" seems to render her perception of names as common nouns or adjectival tags and not as onomastic, persons' proper names. This is not an impairment to do with knowledge (see Kasher and Meilijson 1996, and note 2 above) but a linguistic behavior iconically imaging the autistic objectification of persons and words (see pp. 24-27 below). In the next excerpts, Hadar's use of the second person pronoun (in place of the grammatically expected first person) iconically depicts her mental as well as physical reality:

[5] ani kol ha-zman meyallelet mekateret boxa coeket coraxat ad ha-shamayim doreshet dvarim ani lo yexola lkabel noshexet et acmaex ha-yadayim male siman shel xabalot

Gloss: All time long I whine ${ }_{\{,\}}$grumble $_{\{,\}}$cry $_{\{,\}}$shriek $_{\{,\}}$scream to high heaven $\{$,$\} order$ things I can't get $\{$,$\} bite (all verbs in the prtc. fm. sg. form) herself f_{;\}}$the hands full [of] wound's mark $\{$.

The grammatical formation iconically images the phenomenon of objectification: her body, the hands she bites, as well as the wound marks she notices (made by her own teeth) are experienced as objects external to herself: not "my hands" but "the hands" (see also Bosch, 1970, p. 94). This accords with the apparent absence of an authentic

(one / I)" (in [4]) could be a single case of verbal repair. Alternatively, it could be explained as an unmarked form (ms.) expressing an aphorism, followed by reference to herself (fm.), or it could also be a double statement broken into masculine and feminine. The matter of verbal repair is of importance concerning autistic speakers, as it concerns speech act management (see Keen, 2003) not as raw pragmatic and socio-pragmatic competence (see Kasher and Meilijson, 1996 on repair, and see note 2 above) but as linguistic behaviour originating from I not-I distinction, absence and need. Unfortunately, these issues cannot be pursued here. 
expression of internal pain formed using first person: she reports on observing the wounds but not on sensing them.

The apparent gap between hypersensitivity (see [3] above) and the detachment in [4] is well attested concerning autism in general, and in Hadar's case seems to be settled by the distinction between external tangible sensual stimuli (such as heat or noise) to which she was hyper-sensitive and internal self-inflicted physical pain to which she appeared indifferent (see p. 18 below, but see also pp. 20-24 below).

Excerpt [6] illustrates another situation, iconically expressed by means of the second person possession suffix:

[6] [...] kimaat lo sholetet al acmex

Gloss: [...] almost (literally hardly) not control (prtc. fm. sg.) on (sic., see following [7] below) yourselff.\}

This could well be a case of echolalia (see [2] above), but the qualification of the verb 'control' by what seems an unexpected and inappropriate quantifying adverb "kimaat", as well as the content, reinforces its reading as iconically imaging the lack of control over the self.

A broader sense of detachment emerges in reports such as the one about looking through her own photo album [7] and when reporting dreams [8]:

[7] [...] ha-albom lo shel ha-yaldut Hadar smexa kmo ciyeru oti axrei keev beten [...] cilum al Hadar lifnei ha-shad [...]

Gloss: [...] the album $\{-\}$ not of childhood ${ }_{\{-\}}$Hadar [is] happy like drew (subjectless ps. $3 \mathrm{p}$ pl.) me after [a] tummy ache [...] [a] photo on (sic) Hadar before the breast [...]

The situation of looking through a photo album in general and one own's in particular, seems to amplify the autistic state: the categorical demarcation between looking at oneself and looking at others is blurred, as well as, that between echoing (photo) and imaging (drawing), as the excerpt bears out. ${ }^{14}$ Hadar's grammatical "error" replacing "of" with "on/about" (see also [6] and [15]) further distances her self from the situation, resulting in a story-like reporting about something (not-I).

[8] [...] halaxti lanuax ba-xeder taxat smixa im az xalamti eize xalom [...] Hadar yocet $l$ biluy la-ir beit tixo beit kafe oxelet salat [...] Hadar b-gil axer lifnei ha-mashber shel Sima lo rak im shad axat shtei shadayim bli gushim ba-shad

Gloss: [...] [I] went (ps. 1p sg.) to rest in the room under the blanket with then [I] dreamt (ps. 1p sg.) a dream [...] Hadar goes (prtc. fm. sn.) out [on an] outing to town $\{:\}$ Ticho House (a restaurant in Jerusalem) \{,\} coffee shop \{\} eating (prtc. fm. sg.) salad [...] Hadar in a different age before the Sima crisis $s_{\{,\}}{ }^{15}$ not only with one breast two breasts without lumps in the breast $\{$.

14 This resembles Peirce's example of pure iconicity "So in contemplating a painting, there is a moment when we lose the consciousness that it is not the thing, the distinction of the real and the copy disappears, and it is for the moment a pure dream - not any particular existence, and yet not general. At that moment we are contemplating an icon". (1965, Book 3, p. 211).

15 Hadar refers here to an incident which she associates with a teacher named Sima. Language and Psychoanalysis, 2015, 4 (1), 4-30 
The following modes show up when Hadar refers to herself in her dream report: the grammatical first person verb suffix (see [2] above); her own given name (as if designating a third person) and a zero alternant in place of the missing subject expected (obligatory) first person pronoun ("ani" E: I) of the verb "to eat". The latter results in an impersonal (neuter) form (a "fourth person" as it were), i.e., no specific person.

In her oral speech Hadar's mode of designating her addressee was systematically fixed with no modifications. ${ }^{16}$ As mentioned, she reserved first and second person verbal affixes and pronouns to refer to herself and not to refer to the second person (see above Bosch 1970). Proper name: given name, often followed by family name or by adjectival tags of very specific semantic fields (e.g., "Tamar Ephratt your [referring to her] mother") or the zero alternate resulting in the impersonal, were the two forms Hadar used for referring to second and third person (as said these, along with other standard and nonstandard forms, also served to refer to herself (see e.g., [8] above). Interestingly she scarcely used third person pronouns such as "hi" (E: she); "hu" (E: he); "hem" (E: they) and "hen" (E: they fem.).

The autistic state is iconically reflected not only by the shift of pronouns and pronominal markers but also by the blurring of case roles such as agent and patient. This is illustrated in excerpt [9]:

[9] hitnahagti ha-yom al ha-boker kmo yalda mufraat ktana craxot bexi ceaakot ad hashamayim az ha-cevet ala lax al ha-acabim

Gloss: [I] behaved (ps. 1p sg.) today since the morning like a troubled (fm. sg.) small (fm. sg.) girl (fm. sg.) \{:\} shriek $_{\{,\}}$cry $_{\{,\}}$scream to high heaven $\{$,$\} then the staff got on$ your nerves\{.\}

The content as well as pragmatic roles reveal role switching: her behavior got on her own nerves (in place of the staff's nerves). This excerpt, concluding the matter of first person designation, adds a fifth mode, hitherto not encountered: leaving out herself as an initiator, a human agent. As opposed to zero alternate for unspecified impersonal verbal form, ellipsis, by omitting any trace of the doer, iconically materializes here in the absence of a verb. This entire utterance ([9]) consists of a flat amalgamate of nouns, in

Ever since her childhood, Hadar considers this event as a major crisis.

${ }^{16}$ Hadar use to send out letters on special occasions such as new-year, and thankyou letters. Letters are the typical written appeal to a second person, but it is not by accident that the style of Hadar's letters, which in many respects resembles her oral speech and her diary style, differs tremendously when it comes to stylistic letter writing peculiarities. These peculiarities are further reinforced due to the ceremonial nature of greeting letters: they are not spontaneous, may even be dictated, or phrased, by a member of staff (in the hostel or in the work place). Never in oral encounters did Hadar express any interest in her interlocutor. A letter consisting of formulaic questions such as "How are you doing?" stands out as inauthentic, both in its form (second person pronoun for the addressee) and in its contents. This oddity, firstly for Hadar (as the writer), showed up in one particular letter in which all modes of reference (including one incident of first person pronoun) to the addressee appeared in a mess.

Language and Psychoanalysis, 2015, 4 (1), 4-30

http://dx.doi.org/10.7565/landp.2015.001 
which even the cries and screams a living agent necessarily produces are objectized as detached entities.

This morpho-syntactic iconic structuring serves to point out one more deficiency characteristically associated with the construction of interaction that constitutes the topiccomment (theme-rheme) relations in an utterance. Being aware of the separation of I-notI, the speaker (I) bases the new information she wishes to communicate to the not-I on what she believes to be shared, known information (see Chafe, 1976). The topic of the sentence presents the latter, whereas a distinct predicate provides the new information (rheme). Mastering this division of communicative labor between theme and rheme is part of intersubjective, and thus discursive-pragmatic, competence. ${ }^{17}$ The absence of a theme in [9] deprives the addressee (not-I) of the shared information and prevents the differentiated designation of the doer and her deeds.

Pronoun references are linguistic signs. The odd linguistic - morpho-pragmatic - choice of articles, i.e., mismatch between the two (independent) phases of these signs: the pronominal form and its content (the reference) in autistic speech iconically parallels the autistic state of being.

As explained, unlike mutism (see p. 7 above) any use of language, in so far as it involves signs (resulting from the diagrammatic merging of an independent form with content) is not pure iconicity. Yet, the bringing together of certain independent yet non-arbitrary elements (modes designating self and image of self) is indeed iconic, and thus telling.

\section{Content words vs. grammar markers: soft vs. hard relations}

Being a system of signs language includes two complementary elements: content words and structural-procedural words. Content words are lexemes such as nouns, verbs, adjectives and adverbs, denoting referents in the world. These could be objects or events, real or imagined, internal or external, objective or subjective. Structure words, such as affixes and articles, prepositions, conjunctions and discourse markers, are responsible for structuring the relations in the particular linguistic unit (construct form, sentence or discourse) and so produce hierarchy and cohesion within and among units.

Focusing now on the management of content words and procedural words in Hadar's texts, we notice that the line dividing between content words and procedural words should not be considered categorical. Instead it should be drawn between particles (grammar and discourse markers) governed by formal rules (particular to the specific language) irrespective of meaning, on the one hand, and pragmatically governed markers on the other.

The former constitute the objective and rigid container or skeleton holding the subjective, flexible and changing (speaker and context dependent) content. Hadar's overall linguistic behavior complied with the grammatical rules directly associated with the skeleton: number, tense and gender inflections and other grammatical articles show up where Hebrew grammar (morphology and syntax, see also Kanner, 1943, p. 144) prescribes

${ }^{17}$ This too is of importance concerning the autistic speaker. Due to space constraints the issue of given vs. new in light of the perception of the not-I (as e.g. questionanswer; definite article and proper names vs. descriptions, etc.) cannot be pursued here.

Language and Psychoanalysis, 2015, 4 (1), 4-30

http://dx.doi.org/10.7565/landp.2015.001 
them. But their content does not match the referents and the relations obtaining in the world. As we have seen, once the grammatical forms are determined (such as second person designating oneself) the grammatical agreement rules follow intact. The same also was true regarding prepositions, e.g., [6], [7] and [15], in which case a preposition was syntactically present ("al" E: on / about) but its odd semantic selection was the outcome of her odd perception of herself as a figure in a story or in a photo album.

Conjunctions (such as "and", "but", "if" and "because") are responsible for the coherence of the text, prepositions - half way in between grammar and pragmatics - designate relations. As such, they comprise the textual skeleton. Amir (2014, 75-90) cleverly portrays the autistic syntax as the inverse use of an organ point. A musical organ point is a sustained tone that interacts with the changing music to create polyphony (harmony, disharmony, continuation and shift). ${ }^{18}$ The autistic inverse use of a psychic organ point, says Amir (2014, p. 77)

is $[\ldots]$ a similar phenomenon, in which what was meant to be the framing structure refuses to be erased, to fade and take the status of a background [...] Instead of affording a base for flexibility and renewal - the sustained organ point becomes a dominant, exclusive content.

Conjunctions, linguistically categorized as structure words, constituting the (hard) vertebra - the linguistic skeleton - are therefore expected to be intact in the autistic syntax (on hard/soft see below). But this anticipation is tricky, because conjunctions are not determined by formal grammar but by the flexible semantic and pragmatic relationships which obtain in the world. Moreover, it is the very essence of conjectures to connect and relate (see Amir 2014, 87). Hadar's habit to leave out conjunctions iconically reflects the nature of the (inner) skeleton: the rigid links are there but they are disjoint, failing to carry a firmly integrated narrative:

[10] tiyul shabat mata shel ha-shzifim nixnas li anaf b-tox ha-ayin halxu l-tipul

Gloss: $\{$ on / during\} Sabbath outing \{\} orchard of the plums \{then/suddenly\} [a] branch went into my eye \{\} went (subjectless ps. $3 \mathrm{p} \mathrm{pl}$.) for treatment $\{$. $\}$

The cause and effect link missing in [4a] between "tomorrow removed stitches" and "[I'll] die" or the absence of a temporal conjunction in excerpt [12] below (and see [17][20] below), are classified as structure words, thus belonging to the linguistic skeleton, but reflect the pragmatic (content) relations and states existing in the referent (outer

18 Amir's distinction between hard (syntax) and soft (semantics) tying up with Tustin's (1992, pp. 92-134, and see below) explanation of the autistic dialectical experience of soft $\mathrm{v}$. hard, seems a clear case illuminating the loss resulting from Kasher and Meilijson (1996) isolating syntax being intact in autistic speech and pragmatic impaired from the autistic etiology and context of being, and so overlooking its iconic psychic context (see note 2 above).

Language and Psychoanalysis, 2015, 4 (1), 4-30

http://dx.doi.org/10.7565/landp.2015.001 
world). In line with the omission of conjunctures is the apparent absence of punctuation marks. Punctuation marks are orthographic notations for paralanguistic oral expressions such as prosody and intonation. They belong in the pragmatic discursive phase, which is not governed by grammar rules. The absence of punctuation marks (except for an automatic - ritualized - full stop at the conclusion of each narrative chunk - stating "zehu". (=E: that's it.)) reflects the autistic person's stilted monotonous intonation (along with non-varied facial expressions), all iconic to the autistic state (see DSM-V, 2013, p. 54). As discussed in pp. 24-27, there seems to be iconic similarity between the intricate hard and soft relations in the experience of the person with autism of self and world (content) and the above mentioned linguistic relations between grammatical form and lexical content. Strict compliance with rigid grammar rules is part of the soothing encompassing function of repetition: grammar rules are the ritual of language but when they serve as inverse organ point they expel (inner) content altogether.

\section{Autistic perception of affinity: affection and kinship}

The failed achievement of mature differentiation between I and not-I manifests itself on the psychic intersubjective level in severe deficits in social communication and social interaction and on the external sensory level in "hyper- or hyporeactivity to sensory input or unusual interest in sensory aspects of the environment" (DSM-V, 2013, p. 50).

The autistic mode of being is often described as a glass dome or a cocoon to which the child or person with autism clings as a concrete wrap or shield.

In typically developed language usage, the speaker wishing to contact and communicate with the other, uses the uniform rigid grammar - language skeleton - to support and transmit her unique, individual, flexible creative content: stories, emotions, experiences, thoughts and the constant flow of feeling in the self. It is fascinating to see how in Hadar's autistic expressions the ostensibly plain use of content words, such as words denoting emotions or kinship terms, turns out, when referring to their immediate (linguistic) context, to be a superfluous application. This empties them from their internal-emotional depth, and so all that is left is reference to an external concrete referent. Such was the case regarding will and independence in [2]. We now look at longing:

[11] kaasher mishehu nosea l-xuc la-aarec xodesh wa-xeci shana wa-xeci mi-rov gaaguim xazaqim mkablim harbe matanot

Gloss: When someone goes abroad a month and-a-half a year and-a-half $\{$ \} \{abundant with\} strong longings \{\} (subject omission) receive (prtcp. pl. imprs.) many presents\{.\}

"Strong longings" is a common expression denoting the emotion aroused by the absence of someone close and meaningful, often in the context of travel abroad. But in the specific context such emotionally expressive use of the word is ruled out disclosing instead a rigid concrete give-and-take transaction: physical absence reimbursed with gifts. The phrasing of this excerpt iconically presents this objectization: rigid grammatical articles, such as inflectional number agreement, are intact. Yet not only are prepositions (such as "[for] a month"); cause and effect prepositions or conjunctions (such as "a month and-a-half [and] a year and-a-half") missing, like in the absence of immediate contact with the distant person, here too there are no people: longing is detached from its 
intersubjective personal experience and so described in terms of objects (see Asperger, 1944, pp. 70-78 and note 57 there).

Another typical case is one in which the broader context of an emotion word affords a perception of inner content (emotions) in terms of external - visual appearance. Here is Hadar's report on her mother's visit, when her mother took her to a close-by supermarket for a treat and Hadar misbehaved:

[12] osa carot l-ima mdaberet shtuyot gasuyot zoreket avanim ba-avir [...] az ima baxta mi-rov kaas

Gloss: (subjectless) makes (prtcp. fm. sg.) trouble for Mummy\{:\} talks (prtcp. fm. sg.) nonsense $_{\{,\}}$rude (words) ${ }_{\{,\}}$(subjectless) throws (prtcp. fm. sg.) stones in the air [...] so Mummy cried (ps. $3 \mathrm{p} \mathrm{fm}$. sg) out of much anger $\{$.

Sobbing - shedding tears - is a distinct visual manifestation of (internal) grief. Hadar misinterpreted this appearance as an expression of anger instead of expression of sorrow, because the former is a feeling directed outwards whereas sorrow is internal.

Similar instances of emotional voiding of content words also show up in the resemblance between the autistic state and language preferences of other content words. Here we confine the discussion to a unique group - that of the semantic field of kinship - as it emerges from Hadar's writings. What seems at first to be standard innocent use of kinship content words turns out to render a blurred distant affinity.

[13] [...] doda Bettie xavera shel ima mi-anglia anti Bettie ihayta haxi elegantit

Gloss: [...] Auntie Bettie [a] friend (fm.) of Mummy from England\{.\} Auntie (in English, see note 26) Bettie was (ft. $3 \mathrm{p} \mathrm{fm.} \mathrm{sg.)} \mathrm{the} \mathrm{most} \mathrm{elegant} \mathrm{fr}_{\text {. }}$

[14] [...] ha-xaverot krovei mishpaxa shel ha-axayot sheli Michal ve-Shira b[a]-kita hacofim beit-sefer avdu [...]

Gloss: [...] The friends (fm.) family relatives of my sisters Michal and Shira in the $\operatorname{class}_{\{,\}} \operatorname{scouts}_{\{,\}}$school worked (ps. 3 p pl.) $[\ldots]$

Hadar's frequent use of "friend" along with the mention of kinship terms reveals ignorance of the variations of intimacy holding between I and not-I: the expected distinction between siblings and friends (both belong to peer group) is missing: her mother's sister is a friend, her own sisters' friends are their relatives but not (transitively) her relatives. In light of this estrangement, Hadar's use of the third person possessive pronoun ("your") when referring to her own sister, as in

[15] yesh li zikronot tovim mi-ha-avar al tiyul b-shxunat Talbiya yaxad im Michal axotex Gloss: I have good memories from the past on (sic.) $)^{20}$ a walk in [the] Talbiya neighborhood together with Michal your $\operatorname{sister}_{\{.\}}$

19 The entire excerpt telling of herself is phrased in a style reminiscent of a story mode: subjectless, verbs are inflected as participle feminine singular.

20 See discussion of "al" (E; on) following excerpt [7] above.

Language and Psychoanalysis, 2015, 4 (1), 4-30

http://dx.doi.org/10.7565/landp.2015.001 
seems to be entailed by plain reciting (see pp. 8-10 above) but more so by the blurring of soft - internal - affinity in general and sisterhood in particular. DSM-V (2013, p. 50) lists among the signifiers of autistic spectrum disorder "Persistent deficits in social communication and social interaction across multiple contexts"; "3. Deficitsin developing, maintaining and understanding relationships". The kinship setting as encountered here is iconic to the autistic state because it does not result from lack of understanding and pragmatic skills (see note 2 above) but originates from psychic developmental breakdown in which separation and thus hierarchies of intimacy- from the most intimate (I) to gradually more distant circles within the not-I - were not established and so could not be internally experienced.

Excerpt [16] illustrates the objectization of family relations, rendering the above ([13], [14], [15]) lexical use unequivocal:

[16] harasti et [...] shover galim shel aba davar nadir axat b-mino davar yakar kmo hadubi shel Hedva yakar kmo axot ba-mishpaxa

Gloss: [I] ruined (ps. 1p sg.) [...] Daddy's breakwater [a] rare thing:\} one in a kind ${ }_{\{,\}}$

[a] precious thing like Hedva's teddy-bear $\{$,$\} precious like [a] sister in the family { }_{\{.\}}$

To express what the shiny chrome model of a (dock's) breakwater means to her, Hadar compares it to a sister in the family and to her classmate's teddy-bear. This excerpt is most impressive in the way it captures the nature of autistic objects as opposed to transitional objects. It will shortly feature again regarding iconic analogy and in the synthesis (p. 26 below; see the quote from Bosch, 1970, p. 93).

\section{Thirdness: Language is analogical to the autistic state}

The iconic quality of analogy (Peirce's thirdness) clusters phenomena in which likeness does not inhere in the sign itself, i.e., through direct resemblance between form and contents (as in pp. 10-20 above), but is obtained by intermediate parallelism between two signs: sign A resembles sign B by way of quality X. Metaphor is a classic instance of such relations.

To illuminate the analogical relations that obtain between form (Hadar's language) and content (the autistic state) we look further into the autistic tendency for concreteness and the route of objectization as they operate in Hadar's world and as they manifest by analogy in her language.

Ever since Hadar was small - as she repeatedly said (in complaint and with frustration) and as she described in her diary - she had been oversensitive to heat (sun, stoves, cigarettes, car exhausts). Also she would not tolerate nicknames such as hypocoristic pet derivations of her proper name (such as "Hadari"; "Hadarile") or words of endearment such as "motek" (E: sweetie), labels such as "gveret" (E: lady), not to mention debasing words such as "tipsha" (E: stupid). ${ }^{21}$ She hated and dreaded them and was constantly on

21 See Freud (1913, p. 54-55) words on taboo upon names, where he says that "As was only to be expected, obsessional neurotics behave exactly like savages in relation to names. Like other neurotics, they show a high degree of 'complexive sensitiveness' in regard to uttering or hearing particular words and names; and Language and Psychoanalysis, 2015, 4 (1), 4-30 
guard doing all she could to avoid sensing heat or hearing such words (at times, she would deliberately provoke such situations as an excuse to burst out, ruin an event or draw attention). As Hadar portrays in the following four excerpts, words sting and penetrate, thus, in the same way as heat, forming a threat to the shield".

[17] [...] ha-shemesh ba-xuc yom shel kayic xamsin meod xam 35 maalot kmo erec micrayim ha-sipur shel pesax yeciat micrayim ba-hagada shel pesax ose li dkira ba-yad soref li ba-haref kmo maxat sika xada mashke im gazim bira soda tempo ambatia xama rotaxat akica shel dvora dabur

Gloss: The sun outside: [a] summery day $\{$,$\} heat-wave { }_{\{,\}}$very warm 35 centigrade like

Egypt countryside the story of Passover ${ }_{\{,\}}$exodus from Egypt ${ }_{\{,\}}$Passover legend $\mathrm{P}_{\{.\}}$ makes (=causes, no subject, possibly referring back to the sun) a prick in the hand ${ }_{\{,\}}$

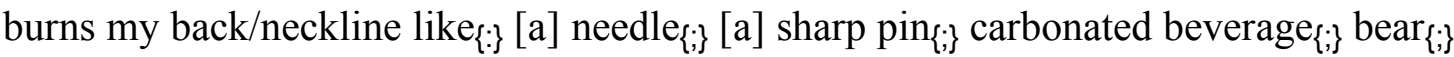

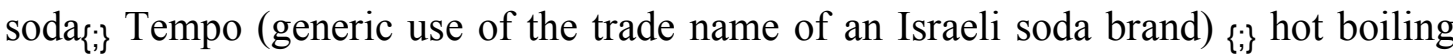
bath $\left\{\right.$ and\} $[\mathrm{a}]$ sting of [a] bee $\left\{\right.$ or\} $[\mathrm{a}]$ hornet $\{.\}^{22}$

[18] lakaxti ugiot shokolad asa li ba-lashon kmo motek kaasher hayiti ktana baxiti cavtu oti amru li motek

Gloss: [I] took (ps. 1p sg.) chocolate biscuits \{this/they\} made (=caused, ps. 3p sg.) me (object of main verb missing) in the tongue $\{. /$ this is\} like \{verb or action missing\}\{the word "\} sweetie $^{\left\{{ }^{\prime \prime}\right\}}\{$,$\} when [I] was (ps. 1p sg) small \{$. / and\} [I] cried (ps. 1p sg.) \{because\} pinched me (subjectless - ps. 3p pl. imprs.) me ${ }_{\{a n d / o r\}}$ said (ibid.) to me $\{:\}\left\{{ }^{\prime \prime}\right\}$ sweetie $\{$.\}

[19] ani yashavti ba-salon raiti toxnit l-yeladim hayta mila ba-ot tet ani haxi sonet kmo eizo dkira shel maxat caakti mi-ze ad lev ha-shamayim

Gloss: I (explicit subject) sat (ps. 1p sg.) in the lounge [I] saw (watched, ps. 1p sg.) [a] program for children \{.\} $_{\text {t }}$ there was [a] word with the letter tet (to avoid uttering "forbidden" words Hadar used to refer to them by their initial letter, she here alludes to the word "tipsha" E: stupid) \{which\} I hate (prtc. fm. sg.) most $\{$.\} \{this felt\} like some prick of $[\mathrm{a}]$ needle $_{\{.\}}[\mathrm{I}]$ screamed (ps. 1p sg.) from this (as a result) to high heaven $\{$.

[20] [...] ha-xom shel ha-mitbax kmo cvita ba-yad o cbitat xiba

Gloss: The heat of the kitchen \{is\} like [a] pinch in the hand or [an] affection pinch $\{$.

The four excerpts lay out the analogical shift between physical sensations (such as heat or a prick) and words. The analogy goes through physical penetration and the existential threat to the fictive frail shield. This parallelism is the outcome of the objectization of words, the iconic sensory perception of sounds - words - as concrete physical objects. But the above words reveal that an additional layer of objectization takes place, and this

their attitude towards their own names imposes numerous, and often serious, inhibitions upon them".

22 On the apparent absence of conjunctions and punctuation marks and the lack of coherence see pp. 16-18 above.

Language and Psychoanalysis, 2015, 4 (1), 4-30

http://dx.doi.org/10.7565/landp.2015.001 
is the materialization of emotions as concrete external objects: sharp, hard and physically penetrating, and not as psychic-internal soft experiences, such as pain or humiliation. ${ }^{23}$

Excerpts [1], [18] and [20] provide a connection to the succession of events that led to the associations emerging in the iconic-metonymic shifts. In these excerpts Hadar alludes to physical pinching (a child's cheek) as a way of showing affection, probably occasionally accompanied by verbal expressions such as pet names. Hadar often expressed her belief that an early experience (aged two, see note 3 above) of shock evoked by a brutal injection had caused her autism. ${ }^{24}$ The affectionate pinch like the unexpected vaccination (see [1]) were both intrusive acts performed by adults, who instead of protecting her, let her down by brutally penetrating her young fragile shield. Through objectization these traumatic experiences were analogically extended to any sudden sense of intrusion (as listed in excerpt [17]).

The high register language, most apparent in the intensive use of idioms, strongly associated with the speech of Asperger individuals has puzzled researchers. The central characteristics of idioms, propagating their use in mundane (non-pathological) registers, are the fact that they are memorized, frozen collocations (not generated by the speaker) and carried over from past cultural heritage (which also explains their figurative vocabulary). Despite the object-based attraction of some persons with autism to sounds (see below) the salience of idioms in the speech of Asperger and other individuals with autism spectrum disorder has nothing to do with esthetic sensitivity or preference (such as hyperlexia). It is the outcome of their iconic use of ready-made segments. This explains why these speakers equally recite slang or even texts in foreign languages (see e.g., Kanner, 1943, p. 238). It is most striking that the non-pathologic sociolinguistic use of idioms and formulaic speech, namely, the speaker's choice in a particular setting of cited segments rather than her own speech, communicates her being part of that heritage and setting (see e.g., Chetrit, 1995). The noteworthy citing of idioms, of other's utterances and the rigid use of formulaic speech in verbal individuals with autism spectrum disorder communicates a break, starting from her most intimate circle, namely herself, up to society as a whole.

But, specifically, regarding idioms, it is not only citing that propagates their use by verbal persons with autism, but it is their phraseological quality, namely the gap between their idiomatic figurative meaning and the joint meaning of their constituents (literal meaning).

Hadar incorporates many idioms into her speech and writing. Idioms such as "a smile on the face from ear to ear" (in fact two separate idioms joined) (likewise see "grumble cry shriek scream to high heaven" [6], [17] below) are perceived and introduced in their

23 The similarities between this iconic objectization and the phenomenon of nominal realism, the nature of the particular words (see Segal, 1957) and the matter of taboo words, are beyond the scope of this article (see note 21 above).

${ }^{24}$ It could well be that the vaccination incident to which Hadar alludes ([1]) was traumatic not so much because of the nurse but due to the traumatic tearing of the mother-child symbiosis facing her own mother letting her down as she merely stood by leaving her helpless. This is another case (see note 12 above) in which Hadar refers to her autistic state. It seems particularly interesting, as it might shed new light on the ongoing debate concerning association between MMR vaccination and autism (see e.g., Richler et al., 2006 and see also Kanner, 1943, pp. 244-245).

Language and Psychoanalysis, 2015, 4 (1), 4-30

http://dx.doi.org/10.7565/landp.2015.001 
literal meaning. The autistic speaker performs a reverse analogy, from the idiom back to the constituents. The reverse analogy iconically conveys, through objectization and concreteness, the autistic intake of the external.

Moreover, literal - concrete - handling of idioms expressing emotions and internal states, e.g., "a smile from ear to ear", is in line with Temple Grandin's recollection regarding her social skills training, when her aunt labeled each facial expression appearing on photos of Temple with the appropriate emotion-word. Temple's aunt used these to direct Temple, e.g., when the mouth spreads upwards this means that the person is happy, and if downwards she is sad, etc (see [12] above).

We conclude this discussion of analogical iconicity following the objectization of words by pointing out that very early on (between age 5 and 9) Hadar made up about a dozen neologisms that served her from then on to refer to states for which one would conventionally use emotion words. Hadar generated these neologisms ${ }^{25}$ using two strategies: one was by distorting English words ${ }^{26}$ as in "idevel" to denote terrifying incidences, originating no doubt from the word "devil"; "pik" to denote the sense of sharp and stunning penetration, coming from "prick", and "rodingdang" after "rod" (smooth and shiny) denoting something (not necessarily tangible) to be enthusiastic about. ${ }^{27}$ The second group of neologisms bore no etymological relation to either existing English or Hebrew words; they were made up from scratch on the basis of secondary phonetic iconicity: back - grave - vowels ("o" and " $u$ ") for the expression of negative horrific feelings (e.g., "iguzi" 28 for a dancing shade reflected at night from a distant lampshade) and front high vowels (mainly " $i$ ") for positive ones (e.g., "chipichipi" her sister's sore toe which amused her). Such expressive sound symbolism accords with linguistic literature (for overview see Jakobson and Waugh, 1987, pp. 181-198) but seems counterintuitive to typical autistic clinging - as Amir's (2014; and see above) inverse organ-point - to the hard i.e., consonants (and not soft - i.e., vowels). "Rodingdang" explained above could serve to settle this seeming discrepancy. To derive this neologism Hadar added repetitive stop (plosive) consonants to the (given) base "rod" alternating vowels: " $i$ " and " $a$ ". The resulting sound pattern accords with Hebrew (Semitic root and pattern formation) function of the vowels (rather than consonants) as the organ-point carrying the semantic variation of meaning. From a psychological perspective, the word "rodingdang" starting with the iconic " $o$ " vowel (expressing graveness), moving on to " $i$ " (signaling cheerfulness) may reflect the uncanny autistic state by analogical iconicity: as mentioned Hadar was hypersensitive to heat, and her idiosyncratic autistic objects (hard and shiny) were themselves sources of heat: car exhausts, toast racks, candlesticks, or taps which being made from metal attracted - and so released - heat. The sound symbolism and the intricate relations between the hard stops (consonants) and the soft vowels in

25 It is interesting to note that the term "neologism" originated in the context of abnormalcy. Webster's dictionary states: "a usually compound word coined by a psychotic and meaningless to the hearer" (Gove, 1986, p. 1516) and see Freud, 1900 p. 296 fn. 2.

${ }^{26}$ Hadar was raised bi-lingually in Hebrew and in English. Living in Israel Hebrew was her dominant language out of home. Yet, she often mixed these languages both orally and in writing.

27 See excerpt [16] and the discussion on pp. 24-27 below concerning autistic objects.

28 The recurrent final " $i$ " acts as the Hebrew adjectival suffix.

Language and Psychoanalysis, 2015, 4 (1), 4-30

http://dx.doi.org/10.7565/landp.2015.001 
"rodingdang" iconically reflect the uncanny attraction and dread (Freud's "Scheu") such objects entailed. ${ }^{29}$

The seeming antinomy between the creative faculties manifested in neologisms and the manifest renewal in general and imaginary play in particular, said to be blocked for persons with autism, is settled if we bring to mind that typically developing young children make up words out of ignorance (being unfamiliar with the conventional lexicon). As the children get familiar with the conventional - adult - words they give up these private words. Older autistic persons seem to be stack freezing the first stage: they go on using these childish neologisms, not replacing them - as anticipated - by the common words on the one hand and not generating more neologisms on the other. Their continued use of their infant neologisms is rudimental of what Tustin (1992, p. 188) describes, regarding autistic objects, as "the result of primary creativity having gone wrong".

A discussion of sound symbolism concludes our overview of analogic iconicity along with an overview, findings and analysis of the different types and examples of linguistic iconicity in the data.

\section{A synthesis of autistic iconic speech and the autistic etiology}

We devoted the previous section (pp. 7-24) to the analysis of typical autistic language behaviors, from muteness as pure icon, through echolalia, to grammatical and semantic characteristics demonstrating similarity (secondness) and analogy (thirdness) to autistic states.

Unsurprisingly the DSM outlines diagnosis and assessment criteria for mental disorders, but looks into etiology issues (such as genetic or circumstantial information) only to the extent this is required to either support or rule out diagnosis. This is true for the DSM in general and in the case of ASD in particular (see note 2 above). The DSM-V's denominators helped us detect manifestations of linguistic signifiers in Hadar's writings and analyze them locally; it helped us identify the nature of their iconicity and explain them as such.

Having identified these iconic pathologies from a linguistic-iconic perspective, a step forward is now taken by integrating the findings into a comprehensive picture in light of the autistic etiology.

29 Occelli et al. (2013) found that people with autistic spectrum disorder performed just above chance in the classic Maluma-Tacket test (a test matching twodimensional visual images with nonsense words). Bearing in mind autistic prevalence of visual perception, this seems surprising. It could well result from clinging to a single sound as inverse organ-point (see Amir, 2014), and ignoring its effect in interaction with complementary sounds (such as stop vs. liquids; hard vs. soft), or to methodological shortcomings when administrating artificially structured experiments to people with ASD (this critic also concerns Kasher and Meilijson's (1996) paper and their reliance on empirical studies in particular).

Language and Psychoanalysis, 2015, 4 (1), 4-30

http://dx.doi.org/10.7565/landp.2015.001 
In regard to speaking individuals with ASD DSM-V (2013, p. 53) states that "[e]ven when formal language skills (e.g., vocabulary, grammar) are intact, the use of language for reciprocal social communication is impaired". Scholars raise serious doubts concerning the likelihood that autistic speech can truly be intact. Pragmatic and conceptual intactness should be considered an additional phase between the two types of intactness outlined in the quoted reservation from the DSM: language skills and the communicative-social use of language. Mismatches, such as the cases outlined above (pp. 7-24) (co-reference between the personal pronoun and the denoted referent) or the conceptualization following (internal) discrimination between "friend" and "relative" come neither under language skills nor under communicative-social use of language. They stem from the autistic state of being interfering with the pragmatic and conceptual phase of language. The issue at hand is not the lack of linguistic competence or cognitive deficits blocking understanding. Labeling such behavior as odd is justified when compared not with regular speech but with typically developed differentiation between Inot-I and more so with non-pathologic psychic development. As stated at the start, attempting to understand (prior to intervention and healing) autistic linguistic behavior from a semiotic-iconic perspective, mutism appears the pure iconic mode of the autistic experience (see also Kanner, 1943, p. 244; Amir, 2014, p. 79). For the person with autism, blocked from early normal psychological development by an abnormal fusion with the mother and lacking a background presence of primary identification (see Tustin 1992, p. 33), language and interaction are not authentic to her inner psychic state. As the person with autism fails to proceed ${ }^{30}$ to mature, healthy separation and intimacy (I not-I) any engagement in language is altogether odd.

This is why the authentic language of speakers with autism (those who do speak) is following Amir's words (2014, referring to various psychic languages) - "an attack on language", embodying an ever-suspended state of being cut-off from pathological symbiosis without maturely arriving at individuation. Such language is thus omnipotent. Lacking dyadic object relations, it cannot connect. This results in a language detached from self (I's inner world); the language of a speaker who is not motivated by the experience of absence (I not-I separation, see the quote from Amir, 2014, p. 1, on p. 7 above), and so a language that does not communicate (the I to the not-I).

To delve into the autistic authenticity of the non-authentic - odd - use of language (and language behavior) we look at excerpt [21] (Illustration 1):

[21] [...] baxiti lama yacaati adam lama noladti adam raciti lihyot buba o kelev caacua o sil o misxak yeladim o davar asu oto b-beit-xaroshet mi-xomer [...]

Gloss: [I] cried (ps. 1p sg.) \{:\} \{“\}why did [I] come out (=emerge, ps. 1p sg.) a human-

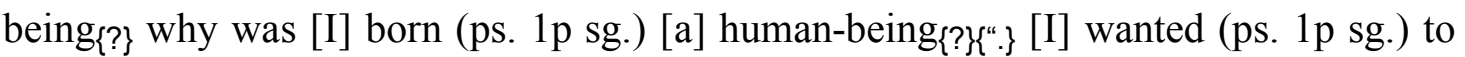
be [a] doll or [a] toy dog or [a] seal (in English, = seal toy) or children's game or a thing $\{$ that it was made (subjectless ps. $3 \mathrm{p}$ pl. impers.) in a factory out of material [...]

Things - artifacts - are static: they lack the capacity to feel, interact (with an inner self as well as with

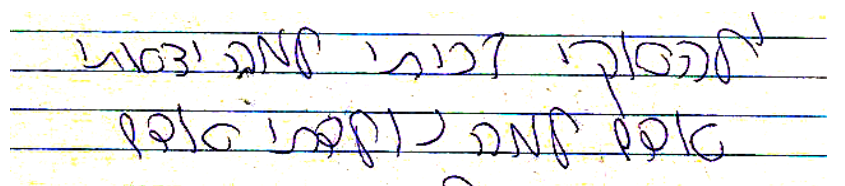

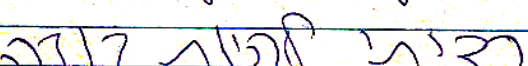

30 That is only individuals clinically diagnosed with ASD and not individuals diagnosed for other impairments (e.g. physical organic, mentall) ? $\sqrt{\mathrm{C}}$

Language and Psychoanalysis, 2015, http://dx.doi.org/10.7565/landp.2015.r

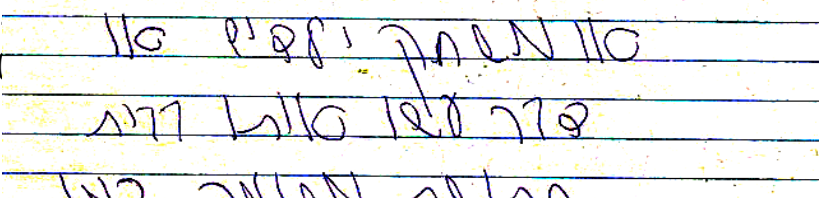


the not-I) and accordingly, they do not adjust and grow. As shown, the language -form and content - of persons with autism authentically iconizes their state as objects rather than living persons. Examining the list detailed in excerpt [21] further reveals this iconicity: dolls and toys are artificially manufactured things, but like the autistic experience (and language) they mimic, and thus they belong in the realm of the animateinanimate. This brings us back to the autistic objects discussed following excerpt [16]. Scholars and caretakers have noticed the early preference of toddlers and children with autism for hard inanimate objects over Winnicott's "transitional objects". Tustin (1992, pp. 111-126) describes "autistic objects" as sensation-dominated objects particular to each individual child, who uses them obsessively in idiosyncratic ways, which also differ from the function for which they were manufactured and intended. Due to the rigid sensory and static quality of autistic objects play and fantasy are blocked and so they impair mental development. Tustin continues, "the main purpose of autistic objects is to shut out menaces which threaten bodily attack" (p. 115, see also Kanner, 1943, pp. 246250; Amir, 2014, pp. 67-90). Hardness, when detached and emptied from softness, (a denominator of autistic objects) constitutes an illusive pseudo-protection. This yields omnipotence that stops the child from seeking contact with people. This description of autistic objects highlights how they are the reverse of transitional objects: the latter serve as a bridge to reality whereas the pathological use of the former acts like a barrier to it. Moreover, being inanimate inflexible objects they tend to break irreparably, an experience that blocks the child's prospect of growth and recovery. This dead-end, according to Tustin, is the source of the psychotic child's despair (p. 121, see also the quote from Tustin, p. 24 above, and see also Amir, 2014, pp. 70-72).

Bosch (1970, p. 93) points out that "autistic children are disturbed in their relationship with other people but not with things, and that this relationship with things has been transferred to people" (but see p. 105). In light of excerpts [16] and [21] it seems that this relationship with things is not merely transferred to people in general, but first and foremost to the autistic (impaired) self. As claimed above regarding autistic language, which is never completely free of oddities, this psychic-constitutional endowment affects and so disturbs all perceptions and relations. Being cut off from the animate-inanimate distinction not only objectizes and concretizes everything (self, other people as well as language) but as Bosch (1970, p. 106) claims, this in turn distorts her relation with things, as the hard complementing the soft. Tustin (1992, pp. 92-134) points out the formative developmental role of tolerating the fact that both soft and hard are "me" experiences, which enables coming to terms with the conflicting pleasure principle and reality principle, thus getting primary differentiation and integration going.

Hadar used language to express her resentment of being born human rather than inanimate: a substance artificially manufactured [21]. This is not a matter of preference but an authentic reflection of the autistic etiology manifested in objectization. On several pages, where Hadar spells out the differences between the course of her life and that of her two twin sisters, she mentions that she did not - and will not - get married. She then narrates her vision of a normal life: she would have a husband, children and a house/home with taps, a toast rack and shiny candlesticks. This as [16] illuminates is an identification of soft inner relations, which in the case of Hadar is typically experienced by and among people with hard concrete objects. Moreover, Hadar's inventory of home life poignantly demonstrates the distorted identification of possessing things (hard artifacts) with intimacy (soft compassionate coupling, family bond and home partnership).

Language and Psychoanalysis, 2015, 4 (1), 4-30

http://dx.doi.org/10.7565/landp.2015.001 
Dana Amir (2014) identifies concrete language and pseudo language as two fundamental non-languages that negate language, as an attack on linkage (communication). For lack of space, we must abridge Amir's elaborate and most relevant account. Amir characterizes concrete language as a functional, yet emotionally meaningless language, resulting from a hollow mother-infant unit, lacking "a substratum upon which a child can establish a private language or an experience of an 'I"'. Pseudo language, says Amir, emerges from "a mother-tongue [that] was unable to give any object a stable and unambiguous status", and so its function is to "[empty] language of its ability to illuminate distinctness. Blurring the limit between self and other is in the service of both the refusal to see the other as well as the refusal to see oneself" (2014, pp. 6-9). Regarding both pseudo language and concrete language, Amir (2014, p. 3) maintains, "the lack of emotional authentic language is the enactment of an unbearable primary bond" (see also Asperger 1944 , p. 70). The autistic linguistic behavior outlined here on the basis of Hadar's writings emerges as a non-language characteristically merging pseudo language and concrete language, thus mirroring how hypersensitivity and detachment dwell together in the autistic state. Mutism is the most authentic - and iconic - mode enacting the traumatic autistic rupture of the delusory symbiotic state and what Tustin (1992, p. 12) describes as a state not fully born. In this premature frail encapsulation the counter-iconic use of language is in itself a pseudo use: "a language one can use to speak - but not to converse with" (Amir, 2014, p. 10). Detached from soft inner meaning and dealt with by means of objectization, the content materializes as concrete language.

It must be noted that it is not the wording that counts, but the idiosyncratic context and circumstances in which the specific utterance appears. The very same word or phrase may either reflect concreteness or manifest pseudolangauge; at times it is an appearance of reluctant communication while at other times it may underwrite rigid compulsive behavior that comes to struggle against the feelings of void associated with traumatic separation, or serves to act as an assuring holding envelope. In yet other cases, like the idiom and formulaic speech, pseudo-language assumes the language of the other where inner speech is expected, simultaneously reflecting rigidness and objectization. Hadar did not use first person pronouns or articles when referring to others; except for formulaic, hence ritualized, letter writing patterns, she reserved second person pronouns and articles to herself, and as detailed, she used third person and proper name for all (self and others). Through restricting first and second person to herself, the concrete, emotionally hollow languages produces the I while the pseudo-speaker utters the second person.

\section{Conclusion}

The oddities of autistic speech (grammatical, semantic, pragmatic, stylistic odd forms or mismatches) genuinely reflect the unnatural foundations of the interaction of the person with autism in general and her verbal communication in particular. Tustin (1992, p. 118), explaining the effect of the use of the pathological autistic object, in place of soft transitional objects, says that "such a child expects to do everything at the first attempt without any practice away from the actual situation". Language, as a mature substitute for bridging separation (I-not-I), finds the person with autism unprepared and displaced: she lacks the required conditions like for instance having passed through the developmental psychic stages and experiences that lead to separation and integration. The unsuccessful separation impairs the ability to confront loss, which in turn impairs motivation in general and interaction with the other in particular. This sequence of failures results in detached

Language and Psychoanalysis, 2015, 4 (1), 4-30

http://dx.doi.org/10.7565/landp.2015.001 
non-communicative verbalization, in mimicking (a pseudo, not-I language), and in clinging to a hard, fixed, inanimate, concrete language devoid of soft inner contents. The particular speech of the autistic speaker authentically iconizes her inauthentic inanimate stance.

We are fortunate to have Hadar's diary and letters, and refer to Asperger's (1944, p. 67) observation that the autistic personality, despite many individual differences, is highly distinctive, in the hope that Hadar's unique legacy and the semiotic notion of iconicity have joined here to yield a productive fresh view of the order, or the authenticity, of the autistic verbal disorders.

\section{Biographical Note}

Michal Ephratt is a professor in the Department of Hebrew Linguistics at the University of Haifa, Israel. The major focus of her efforts is in the study of silence as means of communication. Her research interests include also linguistic models in non-linguistic disciplines, particularly psychoanalysis, and language in real-life setting, such as verbal iconicity and personal given-names. She has published books and numerous articles, including:

Ephratt Michal, "Linguistic, paralinguistic and extralinguistic speech and silence", Journal of Pragmatics, Vol. 43, 2011, pp. 2286-2307.

Nadav Meir, Ephratt Michal, Rabin Stanley, Shiber Asher, "Names and Narcissism: A Clinical Perspective on How Parents Choose Names for Their Newborn", Names, Vol. 59(2), 2011, pp. 90-103.

Ephratt Michal, "Grice's Cooperative Principle in the Psychoanalytic Setting", The Psychoanalytic Review, Vol. 101(6), 2014, pp. 815-845.

Ephratt Michal, "The Minute-of-Silence as Solidarity and Individuation: A Conceptual Model of an Israeli Ritual", Journal of Ritual Studies, Vol. 29(1), 2015.

Ephratt Michal, “What's in no-name?”, Onomstica Canadiana, Vol. 94(1) 2015. 


\section{References}

Amir, D. (2014). Cleft tongue: The language of psychic structures. (M. Hadar Trans.). London, UK: Karnac Books.

Asperger, H. (1944). 'Autistic psychopathy' in childhood (U. Frith Trans.). In U. Frith (Ed.) Autism and Asperger syndrome (1991, pp. 37-92). New York, NY: Cambridge University Press.

Berman, R. A. (1985). The acquisition of Hebrew. In Slobin D. (Ed.), Crosslinguistic study of language acquisition (Vol. I, pp. 255-371). Hillsdale, NJ: Erlbaum.

Bosch, G. (1970). Infantile Autism (Derek \& Inge Jordan Trans.). New York, NY: Springer-Verlag.

Chafe, W. L. (1976). Givenness, contrastiveness, definiteness, subjects, topics, and point of view. In C. N. Li (Ed.), Subject and topic (pp. 25-55). New York, NY: Academic Press.

Chetrit, J. (1995). Dire proverbial et dire personnel. Pour une socio-pragmatique du proverbe. In Bat-Zeev Shyldkrot H. \& L. Kupferman (Eds.), Tendances récentes en linguistique française et générale (pp. 121-133). Amsterdam, Netherland: John Benjamins.

Clark, E. (1978). From gesture to word: On the natural history of deixis in language acquisition. In J. S. Bruner \& A. Garton (Eds.), Human growth and development: Wolfson College Lectures 1976 (pp. 85-120). Oxford, UK: Clarendon Press.

Peirce, C. (1965). The Collected papers of Charles Sanders Peirce (1931-1966). Cambridge, MA: The Belknap Press of Harvard University Press.

Cruttenden, A. (1977). The acquisition of personal pronouns and language 'simplification'. Language and Speech, 20, 191-197.

Davidovitch, M., Hemo, B., Manning-Courtney P., \& Fombonne E. (2013). Prevalence and incidence of autism spectrum disorder in an Israeli population. Journal of Autism and Developmental Disorders, 43, 785-793.

DSM-V. (2013). Diagnostic and Statistical Manual of Mental Disorders. Arlington, VA: American Psychiatric Publishing.

Freud, S. (1935). The interpretation of dreams, S. E. 4-5. London, UK: The Hogarth Press and the Institute of Psycho-analysis. (Original work published 1900).

Freud, S. (1955). Totem and taboo and other works, S. E. 8. London, UK: The Hogarth Press and the Institute of Psycho-analysis. (Original work published 1913).

Gove, P. B. (1986). Webster's Third New International Dictionary - unabridged. Springfield, MA: Miriam Webster.

Jakobson, R., \& Waugh, L. R. (1987). The sound shape of language. Berlin, Germany: Walter De Gruyter.

Kanner, L. (1943). Autistic disturbances of affective contact. Nervous Child, 2, 217-250.

Kasher, A., \& S. Meilijson. (1996). Autism and pragmatics of language. Incontri Cita Aperta, 4/5, 37-54.

Keen, D. (2003). Communicative repair strategies and problem behaviours of children with autism. International Journal of Disability, Development and Education, 50, 53-64.

Lord C., \& Spence, S. (2006). Autism spectrum disorder: Phenotype and diagnosis. In S. O. Moldin, \& J. L. R Rubenstein. (Eds.), Understanding autism: From basic neuroscience to treatment (pp. 1-23). Londo, UK: Taylor \& Francis Group.

Occelli, V., Esposito, G., Venuti P., Arduino G. M., \& Zampini, M. (2013). The taketemaluma phenomenon in autism spectrum disorders. Perception, 42, 233-241. 
Plato, 'Cratylus'. In The Dialogues of Plato (Jowett B. Trans.), (Vol. 1, pp. 173-229). New York, NY: Random House.

Richler, J., Luyster, R., Risi, S., Hsu, W-L., Dawson, G., Bernier, R., et al.. (2006). Is there a 'regressive phenotype' of autism spectrum disorder associated with the measles-mumps-rubella vaccine? Journal of Autism and Developmental Disorders, 36, 299-316.

Segal, H. (1957). Notes on symbol formation. The International Journal of Psychoanalysis, 38, 391-397.

Sellin, B. (1993). Ich will kein inmich mehr sein (Aran Mira Trans. into Hebrew). TelAviv, Israel: Reshafim, 1994.

Tustin, F. (1992). Autistic States in Children. $2^{\text {nd }}$ ed. London, UK: Routledge. 